\title{
Controlling in the management of a regional power grid company
}

\author{
Pavel Sovetov ${ }^{1}$ and Nadezhda Sovetova ${ }^{2, *}$ \\ ${ }^{1}$ Vologda State Dairy Farming Academy named after N.V. Vereshchagin, Vologda, Russia \\ ${ }^{2}$ Vologda State University, Vologda, Russia
}

\begin{abstract}
The tasks of improving the methods and tools of strategic enterprise management determine the relevance of including the controlling mechanism in the process of managing the enterprise's activities. The purpose of the paper is to substantiate the need to use controlling in the process of strategic enterprise management. The authors use general logical methods and research techniques: a systematic approach, generalization, analysis and synthesis. The paper notes the plurality of views of management theorists and practitioners about the essence of controlling and discrepancies in its functional purpose, which entail the problems of organizing and effectively using the controlling mechanism in enterprise management. In this regard, the authors emphasize the view of controlling as a function of strategic management, systematize the list of implemented controlling tasks and factors that predetermine them, indicate the special role and place of controlling as a kind of tool in the analytical mechanism of self-assessment of the effectiveness of the goal-setting and goal-implementing function of enterprise management, the action of which (i.e. tool) is possible with an adjusted feedback model in the control loop. The prerequisites have been identified and a model for the consistent development of controlling in enterprise management has been tested in relation to the object of research - the regional power grid company PJSC "IDGC of North-West". The result of the first stage of mastering the controlling functionality is the ability to partially relieve the top management of the company from operational and technical issues in favor of preparing and implementing management decisions of a strategic focus and content. The spectrum of orientation of the controlling functional in the management of PJSC "IDGC of North-West" towards achieving tactical and strategic goals for the long-term existence and development of the company is shown. Prospects for further research into the problem of organizing effective controlling are in the development of methodological support for the process of integrating information flows using digital technologies. Scientific novelty lies in the presentation of controlling as a management function that ensures the company's activities in accordance with plans in the interests of achieving established goals.
\end{abstract}

\footnotetext{
* Corresponding author: n7777777@yandex.ru
} 


\section{Introduction}

With the growth of the dynamism and instability of the impact of environmental factors in the functioning of enterprises in the real sector of the Russian economy, business entities are faced with the objective need to introduce new methods and tools of strategic management. Nowadays, one of such tools is controlling, which more and more clearly indicates its ability to integrate the processes of information processing, analysis, planning and control in the management of enterprise activities. In essence, the controlling mechanism acts, on the one hand, as a reflection of a new combination of methods and techniques in the implementation of the principles of strategic management, and on the other hand, it allows projecting the possibilities of solving the problem of the long-term functioning of entrepreneurial and non-profit structures in a different plane.

As studies of management problems show, controlling is currently one of the recognized and effective tools of strategic management in many corporations in different countries. Although the concept of "controlling" is quite new in the domestic economy and practice of enterprise management, the controlling mechanism is nevertheless adapted to the modern structure of a Russian enterprise. So, according to the publications of Russian authors $[1,2,3]$, controlling actively positions itself in such sectors of the Russian economy as mechanical engineering, the agricultural sector, trade, energy, etc.

It should be emphasized that the formation of a controlling mechanism in enterprise management is a complex and sequential process, which consists in choosing a methodological platform for its creation, substantiating the organizational model of the constituent components and developing a functioning algorithm. In addition, as noted by some authors, for example, by A.A. Kiselev, [4] the introduction of controlling at Russian enterprises is not consistent with the already established domestic system of organization management and the corresponding domestic scientific terminology, which indicates the ambiguity of its understanding and use in domestic science and practice of the activities of domestic organizations.

Controlling functionality, providing information support for decision-making in order to make the best use of available resources, objectively assess the strengths and weaknesses of the company, as well as prevent crisis situations, remains insufficiently studied and requires the development of methodological approaches and methodological support. The study of the practice of controlling as a functional activity in management at Russian enterprises reveals many organizational and methodological problems. On the one hand, they are individual for each individual enterprise and require the development of specific targeted measures to eliminate them, and on the other hand, they arise from fuzzy target settings for the functioning of controlling, which is differently represented by its content in the minds of managers. Thus, the relevance of the topic of the undertaken research is indicated.

\section{Materials and methods}

To date, among the theorists and practitioners of management, an unambiguous representation of the essence of controlling has not yet developed, which is defined in a wide range of understanding from its initial identification with the control mechanism to the broad area of economic and managerial activity with its inherent relatively fuzzy functional boundaries of its competence, consisting of a set of various indicators and methods of their calculation with the aim of coordinated performance of all management functions at the enterprise.

Nowadays, there is a lot of points of view on understanding the essence of controlling $[5,6,7]$. Moreover, some authors elevate the importance of controlling to a strategic level, which cannot be denied. One can agree with the opinion of M.Sh. Annadurdyev and E.V. 
Erokhina that strategic controlling is a component of the management system for achieving long-term goals of the enterprise, aimed at solving problems corresponding to the chosen strategy of the enterprise and which involves the formulation of goals that reflect the desired state of the enterprise in the future, subject to timely identification and elimination of existing deviations from the purpose of making amendments to the strategy of the enterprise [8]. However, controlling is just the most important element of the management system for achieving long-term goals of the enterprise, which is assigned its own functionality. And it would be correct, in our opinion, to support the current point of view on controlling as a management function that ensures the performance of activities in the organization in accordance with plans in order to ensure the effective use of organizational resources to achieve goals. At the same time, one should not be limited to the use of only organizational resources in the implementation of controlling as a function focused on the management goal.

As the analysis of scientific literature shows, a wide range of points of view on the essence of controlling entails a variety of classification of controlling problems by different authors $[9,10,11]$. The limiter of the classification diversity of controlling functions can, obviously, be the range of management tasks that a particular organization, enterprise or firm sets for itself.

Controlling functions include, most likely, those types of management activities, through which it is possible to achieve the implementation of the assigned management tasks. These include:

- planning and accounting carried out in the interests of achieving management goals;

- organization of control over the process of implementation of plans, including the identification and analysis of deviations of various kinds;

- informing and analyzing the factors and conditions of attainability of the established goals of the functioning and development of the control object;

- assessment of management processes and provision of a report to the person holding a managerial position;

- development of various recommendations that facilitate the making of management decisions, as well as the assessment of the consequences that may arise due to their implementation.

The list and scope of the implemented controlling tasks is predetermined by a number of factors listed by S. G. Falko [1] and received correction in the course of the study:

- economic condition of the company;

- level of understanding by the management and (or) owners of the company of the importance and usefulness of the implementation of controlling;

- area of the market and the situational position of the organization on it;

- level of diversification of production, range of products;

- current level of competitiveness;

- qualifications of management personnel, including persons performing controlling functions.

Thus, controlling in enterprise management occupies a special place: it is, in essence, a kind of self-assessment mechanism of the goal-setting and goal-realizing function of enterprise management, the action of which is possible with an established feedback model in the control loop. In this regard, it is important to ensure the independence of controlling operations in domestic enterprises through direct subordination to the enterprise's management. Such subordination will provide timely information about proposals for making management decisions and the ability to easily communicate with the top management of the enterprise in the interests of monitoring objective standards and critical points of the effectiveness of management systems. 
The construction of a controlling subsystem in a company should be thought out and implemented on the basis of a detailed study of the features of a particular enterprise, its goals and objectives of functioning, problems of selling products and services, as well as the characteristics of the formed organizational structure.

\section{Research results}

The object of the study was the public joint-stock company Interregional Distribution Grid Company of the North-West (hereinafter PJSC "IDGC of North-West"), which operates on the territory of 7 constituent entities of the Russian Federation located in the North-West Federal District: Arkhangelsk Region, Vologda Region, Republic of Karelia, Murmansk Region, Komi Republic, Novgorod Region, and Pskov Region.

The main activity of the Company is the transmission of electricity. As a natural monopoly on the electricity market, PJSC "IDGC of North-West" nevertheless faces the risk of competition with emerging grid companies if several grid companies in the region own grids of the same voltage level. The Company's share in the market for electricity transmission services as a whole across the service area is about $73 \%$, including electricity, part of which is transmitted through the networks of Territorial Grid Organizations (TGO).

Table 1. SWOT-analysis of PJSC "IDGC of North-West".

\begin{tabular}{|l|l|}
\hline \multicolumn{1}{|c|}{ Opportunities } & \multicolumn{1}{c|}{ Threats } \\
\hline - Application and development of & - High dependence of the company's economy \\
digitalization in industry management & on the level of tariffs \\
- Achievement of optimal rates & - Decrease in proceeds from technological \\
- Application of energy-saving technologies & connections due to the completion of large \\
- Increase in the number of new electricity & investment projects \\
consumers & - Changes to areas of legislation governing the \\
- Increasing market share through the & electricity industry \\
consolidation of power grid assets & - Increase in natural phenomena and natural \\
- Formation of a positive image through & disasters \\
direct dialogue with the consumer within & - Unscrupulous guaranteeing suppliers (energy \\
the framework of the portal "Light & sales organizations) \\
Country" & - Expansion of autonomous power supply \\
- Development of interactive consumer & systems \\
services & \\
\hline & \\
\hline \multicolumn{1}{|c|}{ Strengths } & \multicolumn{1}{c|}{ Weaknesses } \\
- Natural monopoly & - Dependence on state policy in the field of tariff \\
- Sustainability of investments in the & regulation \\
company's power grid infrastructure & - Insufficient degree of automation of business \\
- Low level of energy losses & processes \\
- Stable financial condition & - High level of wear of networks and equipment \\
- High level of corporate governance & - Influence of seasonality, climatic and \\
organization & geographic conditions on performance \\
- Qualified personnel & - High time consumption for emergency activity \\
- Positive business reputation in the regions & \\
of presence & \\
\hline
\end{tabular}

Nowadays, stable characteristics of the production assets of PJSC "IDGC of NorthWest" have developed, revealing in the period 2014-2018 a slight increase in the length of overhead power transmission lines (by $0.19 \%$ ), cable lines - by $3.11 \%$, the number of substations with voltage above $35 \mathrm{kV}$ - by $0.34 \%$, the capacity of substations - by $2.28 \%$. The main production indicators of PJSC "IDGC of North-West" have a tendency to increase, the construction of new and reconstruction of existing power grid infrastructure is 
carried out every year. At the same time, special attention is paid to modernizing and improving the reliability of the power grid infrastructure for uninterrupted power supply to consumers, and reducing losses in power grids. The company has a program of continuous training and advanced training of personnel, and a personnel reserve has been formed and is being updated.

The management process in the company is carried out on the basis of the unity of the functioning of all its business processes in the format of an integrated organizational and financial management mechanism. Here, top management personnel show interest in mastering controlling as an activity of systematizing, processing, checking, as well as providing an integrated flow of analytical information of a managerial type to a manager, reflecting the formation of conditions aimed at the long-term existence and development of an enterprise (company). At the same time, the company's management competently motivates enterprise personnel to achieve the planned result (benefit) of the organization, and controlling is positioned as an objectively necessary management tool (technology) that organically fits into the processes of operational, tactical and strategic management. In this regard, it is pertinent to note that the introduction of controlling has also revealed its ability to smooth out and sometimes remove the eternal internal contradictions in the relations between the analytical services of the enterprise - accounting, economic planning and financial.

Here, controlling is perceived not so much as the goal of the control process, but more as a means of taking corrective measures that is formed by trial and error. Being initially focused on providing information and analytical support for decision-making processes in managing a company, controlling "absorbed" the functionality of risk analysis, an extensive set of information support components of the enterprise, as well as a kind of management effectiveness notification model based on the use of key performance indicators and a quality management system. Moreover, the top management of PJSC "IDGC of NorthWest" predetermined the pragmatic possibility of using controlling as a tool for monitoring the factors and conditions of the external environment of the company's functioning, the analysis and assessment of which remained outside the scope of the company's management staff. The orientation of the company inherent to external users and counterparties (supervisory authorities, investors, etc.) was a motivating factor for the "registration" of controlling in the financial and economic block of the management system and initially designated the proven approaches of audit and revision, as well as risk management, as its reference points (Figure 1.2). 


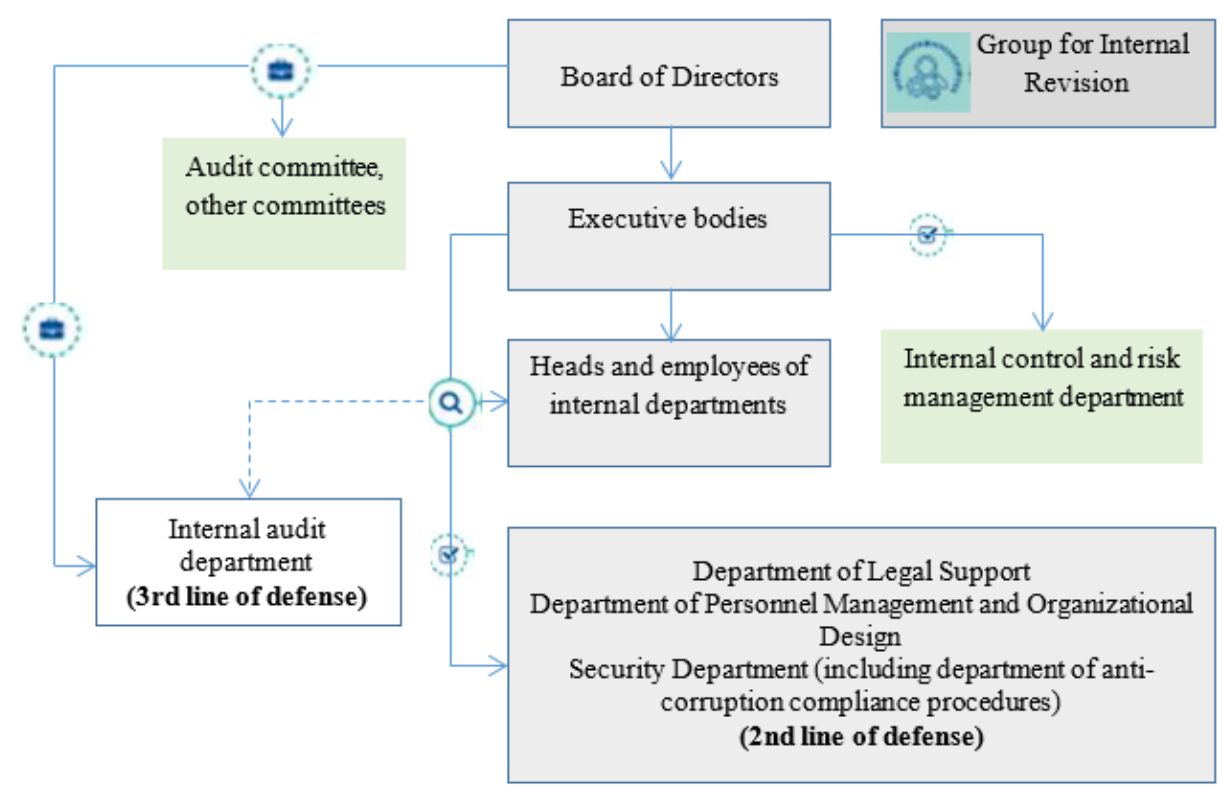

Fig. 1. The main participants in the internal control system at PJSC "IDGC of North-West".

At the same time, among the factors contributing to the development of controlling in management, there was a balanced emphasis on solving short-term and long-term tasks of developing the production of electric power services, manifested by decision-makers, the interest of management in achieving the planned result (benefit) of the company, the perception of controlling as a means of taking corrective measures. At the same time, middle managers, more than other categories of management personnel, indicated their concern that the introduction of controlling would reveal the inefficiency of the work of departments and the personal incompetence of officials of the management apparatus.

However, on the part of the middle management level, there was still a low probability of resistance to measures to introduce controlling functionality into the organization of financial and economic management of the enterprise. Probably, due to the high level of leadership qualities of the chairman of the board of PJSC "IDGC of North-West", there was no discrediting of controlling as a management concept in the eyes of the management personnel. This was largely facilitated by the scientific support of the project, the openness of its goals and objectives, the transparency and accessibility of its conceptual provisions and the stages of implementation tasks. 


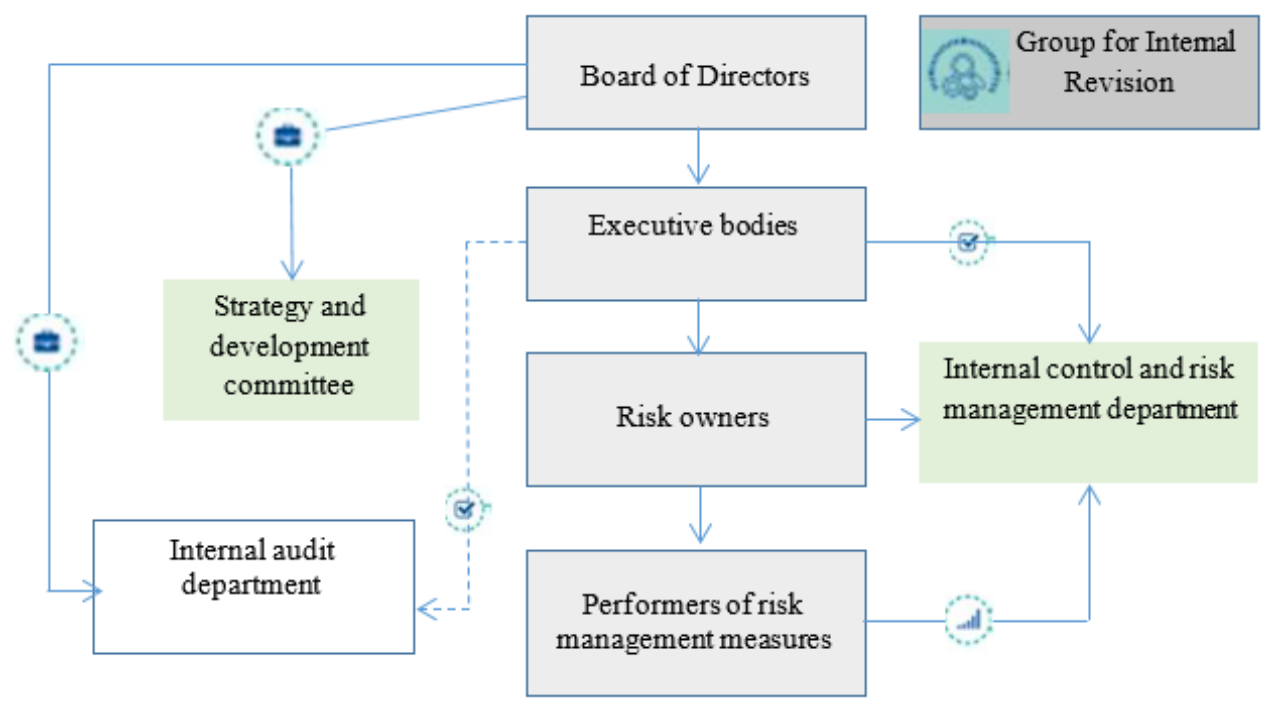

Fig. 2. Key participants in the risk management process at PJSC "IDGC of North-West".

Thus, the first stage of mastering controlling at PJSC "IDGC of North-West" was carried out with an orientation at mastering the well-known economic tools of its action (Fig. 3).

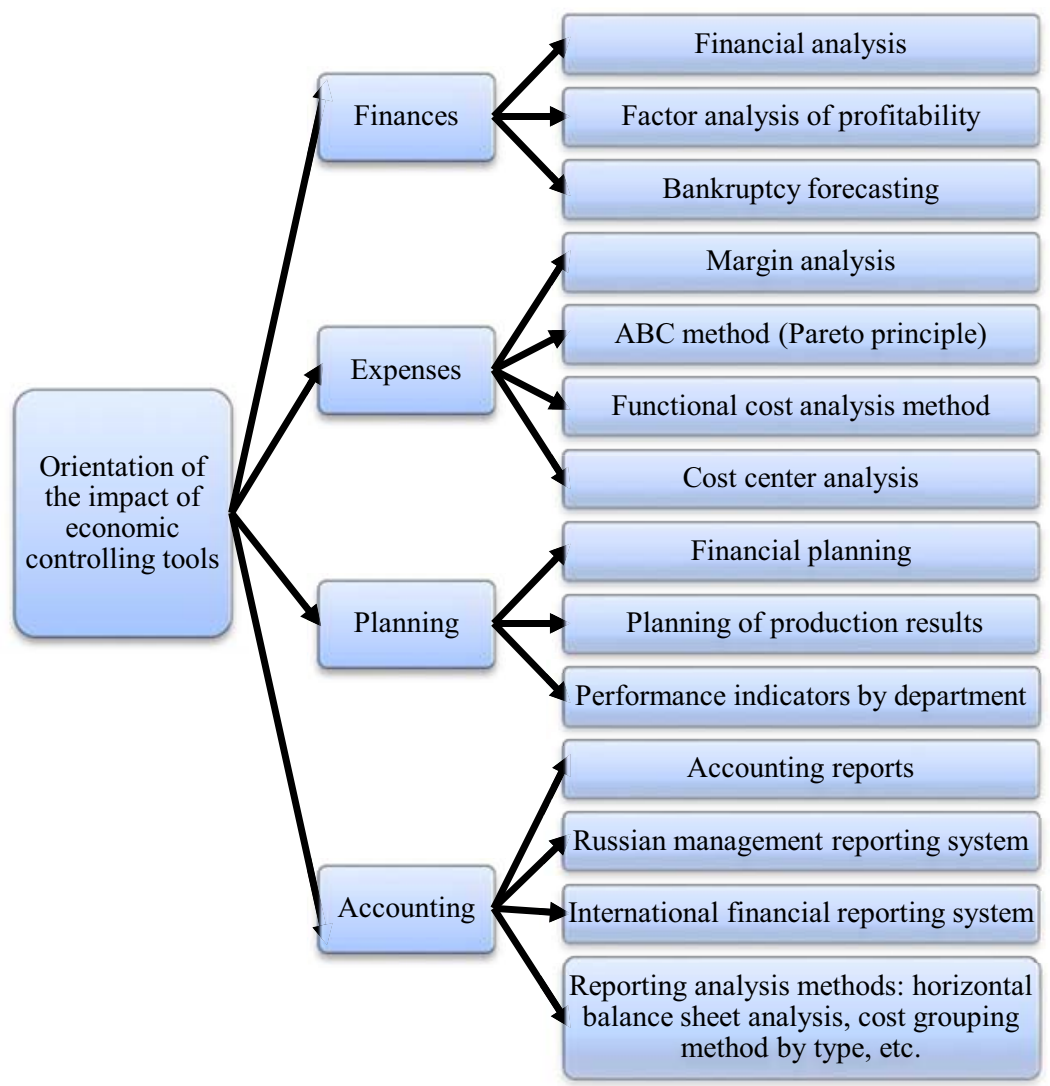

Fig. 3. Financial and economic controlling tools. 
The effective usefulness of the first stage of mastering the controlling functionality has shown itself in accelerating the solution of the tasks of forming a model of a unified information system of the company based on the principles of digitalization, accessible to managers of different management levels in order to achieve their ability to quickly respond to changes in internal and external factors, relying on the integration of the information flow and consolidated internal reporting. Thus, the top management of the company began to project the ability to partially relieve itself of operational and technical issues in favor of preparing and implementing management decisions of a strategic focus and content.

It would seem that the controlling drive is obvious. Nevertheless, one cannot rely only on the enthusiasm of the initiated testing and tuning of the mechanism for solving financial controlling problems. It is necessary to critically comprehend the readiness of the factors and conditions for mastering the controlling model of business processes for the implementation of electricity transmission services at PJSC "IDGC of North-West" in relation to the new challenges and realities of the current problematic situation on the way to achieving strategic goals and requiring its resolution.

Nowadays, the main components of the problematic spectrum of the focus of controlling business processes for the implementation of electricity transmission services of at PJSC "IDGC of North-West" are:

- control of the processes of physical deterioration of power grid equipment and reduction of losses to the level of industrially developed countries;

- tracking the level of achievement of guaranteed reliability indicators and service quality standards;

- monitoring the operating costs of distribution grid companies and the cost of building new facilities;

- digitalization of the energy accounting mechanism that meets modern requirements;

- achievement of the established level of observability and high energy efficiency classes;

- creation of a reserve of transmission capacity of electric grids in a volume that outstrips the development of the economy;

- provision of distribution grid enterprises with qualified personnel.

As you can see, the content of this orientation of the controlling organization in the management of PJSC "IDGC of North-West" seems to be more focused on achieving the following goals of the tactical genre:

- increasing the productivity of enterprise management;

- increasing the degree of management of the company and improving control over the activities of the central office and branches;

- strengthening control over the company's assets and increasing the efficiency of their use;

- reducing the time for making decisions.

At the same time, based on the results of the first stage of this study and movement towards its second stage, it becomes possible to focus on the study of factors and conditions that facilitate (restrain) the implementation of the following main tasks of controlling as a function of strategic management:

- collection of information and systematization of analytical materials on the factors that entail (entailed) deviations in the implementation of the adopted strategy and plans for its implementation;

- preparation of reports and assessments of the efficiency of implementing the enterprise management strategy;

- development of various recommendations that contribute to making management decisions, as well as the assessment of the consequences that may arise due to their implementation. 
Thus, in the study of the problem of organizing effective controlling, the state of integration of the flow of information, analytics and methodological support for creating conditions for supporting the management of the enterprise, aimed at long-term existence and development, will become expressive.

\section{Conclusions}

The choice of PJSC "IDGC of North-West" as an object of research to study the problem of studying the possibilities of mastering controlling in company management is caused, on the one hand, by the orientation of the company's top management to achieve the goals of strategic management, and on the other hand, to the presence of a set of prerequisites and an active position of management to the use of controlling capabilities in the management process, as well as the sectoral features of the functioning of regional energy grid companies.

Let us emphasize that the process of ensuring access of end consumers to the supplied electricity has its own specifics, since in the electric power market, the product - electricity - is intangible, measured only indirectly with the help of specific technical measurement and metering systems. In this regard, the organization of controlling is very important in managing costs, reducing expenses and losses in power grids. In addition, in the "energy sales enterprise - consumer" relationship, the electricity transmission company performs primarily the "financial function of settlements for electricity" and in this case, the technological process associated with ensuring high-quality and reliable metering of the electricity sold and purchased is isolated. Thus, one can quite clearly imagine the scope of application of controlling and designate its functionality, which consists in creating, processing, checking, as well as providing information of a managerial type to management, coordinating planning processes, information support, control and adaptation, helping to solve the problem of effective long-term functioning of the regional power grid company in modern conditions. However, the controlling functionality, which provides informational support for decision-making with the aim of making the best use of available resources, objectively assessing the strengths and weaknesses of the company's activities, as well as preventing crisis situations, remains insufficiently studied and requires the development of methodological approaches and methodological support.

\section{References}

1. S.G. Falkom, Controlling for managers and specialists (Piter, Moscow, SPb, 2015)

2. V.A. Korolev, A.A. Kalashnikov, E.V. Peredereeva, Vestnik of the Voronezh State University. Series: Economics and Management 3, 30-35 (2018)

3. A.S. Lifshits, E.V. Savin, Modern science-intensive technologies. Regional application 3(47), 124-131 (2016)

4. A.A. Kiselev, New word in science: development prospects: materials of the II international. scientific and practical conference (Central od Scientific Cooperation "Interactive plus", Cheboksary, 2014)

5. L. Pinter, P. Hard, P. Bartelmus, Indicators of sustainable development: proposal for a way forward (USD, New York, 2005)

6. The City Development index (CDI). The state of worlds cites. UNCHS (Habitat) (2001)

7. E.V. Konvisarova, T.A. Levchenko, A.V. Rymar, Trends and Management 4, 75-87 (2018)

8. M.Sh. Annadurdyev, E.V. Erokhina, Kant 2(27), 233-236 (2018) 
9. R.V. Nagumova, A.I. Sabirova, Controlling as a modern method of managing subjects of various fields of activity (Kazan, 2016)

10. T. Reichmann, Controlling mit Kennzahlen und Managementberichten: Grundlagen einer systemgesttitzten Controlling-Konzeption (Vahlen, Munchen, 1997)

11. H.G. Kemper, Business Intelligence-Grundlagen und praktische Anwendungen (Vieweg+ Teubner, Wiesbaden, 2010)

12. A.S. Khalepa, Innovative Science 4, 117 (2020)

13. E.A.Borgardt, M.V. Vishnyakova, Vector of Science TSU 1(31), 78-86 (2015)

14. T.A. Khudyakova, Science and business: ways of development 10, 94-96 (2014)

15. Das Controllingkonzept: der Weg zu einem wirkungsvollen Controllingsystem (Horvath \& Partner. Orig. Ausg. München, Beck, 2000)

16. P. Horváth, Controlling (München, 2002)

17. H.-U. Kupper, Controlling: Konzeption, Aufgaben und Instrumente (Stuttgart, 2001) 